\title{
C Research houre \\ Ustekinumab therapy and serum IL-12/IL-23p40 levels for biologic naïve pediatric-onset Crohn disease
}

\section{Akira Shiraishi}

Department of Pediatrics, Graduate School of Medical Sciences, Kyushu University

Masataka Ishimura ( $\square$ ischii@pediatr.med.kyushu-u.ac.jp )

Department of Pediatrics, Graduate School of Medical Sciences, Kyushu University

Katsuhide Eguchi

Department of Pediatrics, Graduate School of Medical Sciences, Kyushu University

Motoshi Sonoda

Department of Pediatrics, Graduate School of Medical Sciences, Kyushu University

Tamami Tanaka

Department of Pediatrics, Graduate School of Medical Sciences, Kyushu University

Takehiro Torisu

Department of Medicine and Clinical Sciences, Graduate School of Medical Sciences, Kyushu University

Shouichi Ohga

Department of Pediatrics, Graduate School of Medical Sciences, Kyushu University

\section{Research article}

Keywords: Ustekinumab, biologics, IL-12/IL-23, pediatric Crohn disease

Posted Date: December 6th, 2019

DOl: https://doi.org/10.21203/rs.2.18034/v1

License: @ (i) This work is licensed under a Creative Commons Attribution 4.0 International License. Read Full License 


\section{Abstract}

Background: The treatment effect of ustekinumab for Crohn disease (CD) that is refractory to tumor necrosis factor (TNF)-a blockers has been approved in adults, but the indication for pediatric cases remains elusive. The present study aimed to assess the applicability of ustekinumab therapy for biologic naïve pediatric patients.

Methods: Four patients who developed CD until 15 years of age and then came to receive ustekinumab as the first-line biologic therapy were enrolled. Clinical and laboratory findings, treatment history, outcomes and adverse events of the biologics were retrospectively studied by using the medical records and interviews to attending doctors. To evaluate the inflammatory profiles at the time of starting ustekinumab, serum concentrations of interleukin (IL)-12/IL-23p40, TNF-a, IL-1 $\beta$, IL-6, IL-8 and IL-10 were measured by the enzymelinked immunosorbent or immunobead assays.

Results: All patients underwent ustekinumab therapy because of the refractory or relapsing disease on conventional therapy and the individual reasons including optic neuritis. Three out of four patients obtained complete remission followed by successful maintenance, although one failed. No adverse events occurred at all. Pretreatment IL-12/IL-23p40 levels of all three responders, but not one non-responder or healthy controls, exceeded $80 \mathrm{pg} / \mathrm{ml}$. On the other hand, the other cytokine levels of all patients were indifferently negligible.

Conclusions: Ustekinumab was effectively used as one of the first-line biologics for the treatment of pediatriconset CD. The limited indication to anti-TNF therapies or the elevated levels of serum IL-12/IL-23p40 may be a preferable choice of the treatment in childhood.

\section{Background}

Crohn disease (CD) is an incurable inflammatory bowel disease (IBD) involving the entire gastrointestinal tract with discontinuous or segmental lesions. The main symptoms of the disease are fever, fatigue, abdominal pain, diarrhea, weight loss and extra-intestinal manifestations. CD occurs in approximately $25 \%$ of patients until 20 years of age. Because the active disease in childhood results in impaired growth, adequate diagnosis and treatment are inevitable [1]. Tumor necrosis factor (TNF)-a blockers have greatly reduced the risk of surgery and complications, although the failure occurs in part of patients. Ustekinumab, human monoclonal antibody that binds with high affinity to interleukin (IL)-12/IL-23p40 subunit induces clinical remission of refractory adult cases via the inhibition of cytokine production and inflammation [2]. However, the effectiveness in childhood IBD has not been established [3], and the applicability for pediatric cases remains elusive. The first-line biologics for the early-onset IBD are challenging to determine because TNF-a blockers often occur in association with infections and immunological disorders [4].

We present herewith the outcomes of four patients with pediatric-onset CD after ustekinumab therapy as the first-line biologics. They had no evidence of primary immunodeficiency diseases, and individual reasons to abstain from the TNF blockade. According to the conditions of four biologic naïve patients, ustekinumab was safely used. Pretreatment serum levels of IL-12/IL-23p40 were increased in three responders. We discuss about the applicability of ustekinumab therapy for pediatric-onset IBD, especially in cases at risk of infections and/or with underlying immunological disorders. 


\section{Methods}

\section{Study subjects}

Thirteen patients age $<20$ years received the diagnosis of CD [2] and underwent biologics therapy in Kyushu University Hospital from 2010 to 2018 [5]. Four of them received ustekinumab as the first biologics for individual reasons. Clinical findings, laboratory data, treatment history, and treatment outcomes were collected from hospital charts. Laboratory indices included: albumin, C-reactive protein (CRP), and erythrocyte sedimentation rate test (ESR), along with serum cytokine concentrations. Pediatric Crohn Disease Activity Index (PCDAI) was calculated as reported [6]. Conventional therapy was introduced in accordance with clinical practice guidelines for inflammatory bowel disease in Japan [7, 8]. The induction dose of ustekinumab was $260 \mathrm{mg}(<55 \mathrm{~kg}$ of body weight) or $390 \mathrm{mg}$ ( $\geq 55 \mathrm{~kg}$ ) intravenously. Eight weeks after induction, the maintenance dose was $90 \mathrm{mg}$ subcutaneously every 8-12 weeks according to the authorized dose for adult patients. This study was certified by the Institutional Review Board of Kyushu University (\#531-01). We were given written informed consent to publish the report by patients and/or their parents if the identities of the patients are protected.

\section{Cytokine Assays}

Serum IL-12/IL-23p40 levels of healthy controls and patients were measured in triplicate using an enzyme-linked immunosorbent assay (Human IL-12/IL-23p40 Immunoassay Quantikine; R\&D Systems, Minneapolis, MN). TNFa, IL-1 $\beta$, IL-6, IL-8 and IL-10 were measured by Human Inflammatory Cytokine Cytometric Bead Array (CBA) Kit (BD Biosciences, San Jose, CA) following each manufacturer instruction as reported [9].

\section{Statistical Analyses}

Statistical difference of serum cytokine concentrations between responded $C D$ patients and healthy or disease controls was analyzed by Mann-Whitney $U$ test. $P<0.05$ was considered statistically significant.

\section{Results}

Clinical profiles of four patients are summarized in Table 1. All received the diagnosis until age 15 years. Two males were siblings, one and the other female suffered from anal fistula and optic neuritis, respectively. No patients showed any evidence of primary immunodeficiency diseases. 
Table 1

Patient demographics

\begin{tabular}{|c|c|c|c|c|}
\hline Patient & 1 & 2 & 3 & 4 \\
\hline Sex & male & male & female & male \\
\hline \multicolumn{5}{|l|}{ At diagnosis } \\
\hline Age, (years) & 4 & 13 & 9 & 12 \\
\hline Weight loss (\%) & 12.5 & 0 & 9.1 & 18.0 \\
\hline $\operatorname{ESR}(\mathrm{mm} / \mathrm{hr})$ & 120 & 25 & 87 & 40 \\
\hline $\mathrm{CRP}(\mathrm{mg} / \mathrm{dL})$ & 11.0 & 0.4 & 5.5 & 0.4 \\
\hline Gastrointestinal lesions & ileum & $\begin{array}{l}\text { ileum and } \\
\text { colon }\end{array}$ & $\begin{array}{l}\text { ileum, colon and } \\
\text { perianal }\end{array}$ & $\begin{array}{l}\text { ileum, colon and } \\
\text { fistula }\end{array}$ \\
\hline $\begin{array}{l}\text { Extraintestinal } \\
\text { manifestation }\end{array}$ & $\begin{array}{l}\text { aphthous } \\
\text { stomatitis }\end{array}$ & $\begin{array}{l}\text { arthritis, skin } \\
\text { nodule }\end{array}$ & & $\begin{array}{l}\text { aphthous } \\
\text { stomatitis }\end{array}$ \\
\hline PCDAl & 62.5 & 22.5 & 57.5 & 32.5 \\
\hline \multicolumn{5}{|l|}{ Previous therapy } \\
\hline First-line & 5-ASA and PSL & 5-ASA and BUD & $\begin{array}{l}\text { 5-ASA, AZT and } \\
\text { PSL }\end{array}$ & 5-ASA and BUD \\
\hline Response & relapsed* & refractory & refractory & refractory \\
\hline \multicolumn{5}{|l|}{ UST therapy } \\
\hline Age at the start (years) & 18 & 14 & 9 & 12 \\
\hline $\mathrm{ESR}(\mathrm{mm} / \mathrm{hr})$ & 70 & 31 & 34 & 12 \\
\hline $\mathrm{CRP}(\mathrm{mg} / \mathrm{dL})$ & 6.5 & 5 & 0.38 & 0.12 \\
\hline PCDAl & 45 & 27.5 & 30 & 25 \\
\hline IL-12/IL-23p40 (pg/mL) & 145 & 151 & 82.8 & 62.4 \\
\hline Body weight (kg) & 60 & 42 & 25 & 32 \\
\hline Induction (mg/kg, i.v.) & 6.5 & 6.2 & 10 & 8.1 \\
\hline $\begin{array}{l}\text { Maintenance (mg/kg, } \\
\text { s.c.) }\end{array}$ & 1.5 & 2.1 & 3.6 & no \\
\hline
\end{tabular}

*The disease activity recurred two years after the stop of first-line therapy at 16 years of age.

AZT: azathioprine, BUD: budesonide, CRP: C-reactive protein, ESR: erythrocyte sedimentation rate, IL: interleukin, i.v.: intravenous administration, PCDAl: Pediatric Crohn Disease Activity Index, PSL: prednisolone, s.c.: subcutaneous injection, UST: ustekinumab, 5-ASA: 5-aminosalicylic acid 


\begin{tabular}{|lcccc|}
\hline Patient & $\mathbf{1}$ & $\mathbf{2}$ & $\mathbf{3}$ & $\mathbf{4}$ \\
\hline $\begin{array}{l}\text { Interval of maintenance } \\
\text { (weeks) }\end{array}$ & 12 & 10 & 8 & no \\
\hline $\begin{array}{l}\text { Duration of UST } \\
\text { (months) }\end{array}$ & 9 & 10 & 21 & only initial dose \\
\hline *The disease activity recurred two years after the stop of first-line therapy at 16 years of age. \\
\hline $\begin{array}{l}\text { AZT: azathioprine, BUD: budesonide, CRP: C-reactive protein, ESR: erythrocyte sedimentation rate, IL: } \\
\text { interleukin, i.:.: intravenous administration, PCD Al: Pediatric Crohn Disease Activity Index, PSL: prednisolone, } \\
\text { S.C.: subcutaneous injection, UST: ustekinumab, 5-ASA: 5-aminosalicylic acid }\end{array}$ \\
\hline
\end{tabular}

\section{Responded cases}

Patient 1 received the diagnosis of $C D$ at age 4 years. During the first induction therapy by prednisolone (PSL) and 5-aminosalicytic acid (5-ASA), he required an ileal resection and temporal ileostomy because of the perforation, and then came to achieve a remission on the maintenance therapy of 5-ASA, PSL and 6mercaptopurine (6-MP). All medications were discontinued at age 16 years. Two years after the cessation of treatment, CD relapsed and did not respond to 5-ASA and budesonide (BUD). Despite the normal results of immunological screening, the inborn errors of immunity were not excluded for the siblings of patients 1 and 2 . TNF-a blockers were then not selected to reduce a risk of infections [4]. Initial intravenous dose of $390 \mathrm{mg}$ $(6.5 \mathrm{mg} / \mathrm{kg})$ ustekinumab successfully led to a complete remission that continued on the subcutaneous maintenance dose of $90 \mathrm{mg}(1.5 \mathrm{mg} / \mathrm{kg})$ every 12 weeks (Fig. 1a).

Patient 2, a younger brother of patient 1, was admitted to our hospital because of arthritis and skin nodules at 13 years of age. The intensive study reached the diagnosis of $C D$. The active disease was refractory to 5-ASA and BUD. Induction of initial dose of $260 \mathrm{mg}(6.2 \mathrm{mg} / \mathrm{kg})$ ustekinumab led to complete remission that continued on the subcutaneous maintenance dose of $90 \mathrm{mg}(2.1 \mathrm{mg} / \mathrm{kg})$ every 10 weeks (Fig. 1a).

Patient 3 suffered from left optic neuritis with elevated levels of anti-myelin oligodendrocyte glycoprotein antibody at age 8 years. There was no gastrointestinal symptom at that time. Intravenous high-dose methylprednisolone and oral PSL therapies controlled optic neuritis, however, high fever, abdominal pain and diarrhea occurred 9 months after the stop of PSL. Intensive gastrointestinal and neurological studies reached the diagnoses of CD and non-active optic neuritis. The poor response to 5-ASA, azathioprine (AZT) and PSL suggested a need of biologics. Because anti-TNFa antibody was not a choice for the patient at risk of demyelinating disease, intravenous dose of $260 \mathrm{mg}(10 \mathrm{mg} / \mathrm{kg})$ ustekinumab was started [10]. Complete remission has been achieved and sustained on the subcutaneous maintenance dose of $90 \mathrm{mg}(3.6 \mathrm{mg} / \mathrm{kg})$ every 8 weeks as shown in Fig. 1 a.

\section{Unresponded case}

Patient 4, a 12-year-old boy, presented with aphthous stomatitis, diarrhea, bleeding and abdominal and anal pain and received the diagnosis of CD. The active disease did not respond to 5-ASA and BUD. Severe food allergy and atopic dermatitis in this patient made us choose comparatively safe biologics $[4,11]$. Induction of ustekinumab dose $260 \mathrm{mg}$ ( $8.1 \mathrm{mg} / \mathrm{kg}$ ) intravenously was started, however, he deteriorated with elevated PCDAI with the development of anal fistula (Fig. 1a). Because of the lacked evidence of treatment effect on anal fistula 
by ustekinumab, the biologics was changed to adalimumab [12]. It has successfully controlled the disease activity for 5 months. No adverse effect occurred in all four patients.

When serum cytokines were measured at the time of starting ustekinumab therapy, three responders but not one non-responder showed higher levels of IL-12/IL-23p40 than healthy controls $(p<0.05)$ (Fig. 1b). Serum levels of TNFa, IL-1 $\beta$, IL-6, IL-8 and IL-10 were negligible in all four patients (Table 2). TNFa levels were undetectable in patient 4, who did not respond to ustekinumab but adalimumab. All responders showed $>30 \mathrm{~mm} / \mathrm{hr}$ ESR at the introduction of ustekinumab (Table 1, Fig. 1a).

Table 2

Serum concentration of proinflammatory and anti-inflammatory cytokines

\begin{tabular}{|c|c|c|c|c|c|}
\hline Patient & 1 & 2 & 3 & 4 & Controls: median, range \\
\hline $\mathrm{TNFa}, \mathrm{pg} / \mathrm{mL}$ & 14.3 & $<3.7$ & $<3.7$ & $<3.7$ & $<3.7,<3.7-430$ \\
\hline IL-10, pg/mL & $<3.3$ & $<3.3$ & $<3.3$ & $<3.3$ & $<3.3,<3.3-9.1$ \\
\hline $\mathrm{IL}-6, \mathrm{pg} / \mathrm{mL}$ & 788 & $<2.5$ & $<2.5$ & $<2.5$ & $26,<2.5-2229$ \\
\hline $\mathrm{IL}-1 \beta, \mathrm{pg} / \mathrm{mL}$ & 31.5 & $<7.2$ & $<7.2$ & $<7.2$ & $<7.2,<7.2-1542$ \\
\hline $\mathrm{IL}-8, \mathrm{pg} / \mathrm{mL}$ & 6837 & $<3.6$ & $<3.6$ & $<3.6$ & $727,44-133506$ \\
\hline
\end{tabular}

\section{Discussion}

This case-series first reported the safety and efficacy of ustekinumab for pediatric-onset CD as a first biologics and a possible relationship between treatment responses and cytokine profiles. Notably, all responded cases but not one non-responder showed high levels of serum IL-12/IL-23p40 and elevated ESR before ustekinumab therapy. These suggest the clinical utility of IL-12/IL-23p40 blockades for the treatment of IBD in childhood, although the indication needs to be individualized.

There are a limited number of pediatric cases who received ustekinumab therapy. Chavannes et al. [13] reported that $21(48 \%)$ of 44 pediatric patients who had been intolerant CD to at least one biologics showed an initial response, and 8 (39\%) of them achieved prolonged clinical remission by subcutaneous ustekinumab. Clinical remission rate of adult patients naïve to anti-TNF antibody reached about $70 \%$ after ustekinumab therapy [12, 13]. By contrast, the remission rates of anti-TNF antibody as the first biologics for adult patients with CD ranged from 40 to $70 \%$. It is difficult to compare the effects of ustekinumab with those of other biologics because of no direct head-to-head trials [11]. In pediatric cases, the response rates to biologics might be lower than adult ones if monogenic IBD was incorporated into the study population [14]. The major concern is a risk of prolonged biologics therapy for children. Several clinical trials $[11,13]$ reported the long-term remission, low immunogenicity rates and low incident of adverse events in ustekinumab therapy, suggesting a favorable choice of ustekinumab for pediatric-onset CD. It is preferred for patients with the history of psoriasis or demyelinating diseases including multiple sclerosis and optic neuritis because anti-TNF antibody has a risk of exacerbation in 
such underlying diseases [10]. Primary immunodeficiency diseases presenting with early-onset IBD need to be excluded before the use biologics for pediatric-onset CD.

IL-12 and IL-23 play an important role in innate immunity. Ustekinumab fully human monoclonal antibody specifically binds to p40, common subunit of IL-12/IL-23, and neutralizes the bioactivity of IL-12/IL-23 which is closely associated with active IBD [15]. High concentrations of circulating ustekinumab by intravenous induction might effectively suppress IL-12/IL-23 pathway and lead to a prompt remission of responders [3, 12].

\section{Conclusions}

The case-series first indicated a relationship between IL-12/IL-23p40 levels and the efficacy of ustekinumab. Further studies would be targeted for the response rates of selected patients with elevated IL-12/IL-23p40 levels.

\section{Declarations}

\section{Ethics approval and consent to participate}

This study was certified by the Institutional Review Board of Kyushu University (\#531-01). We were given written informed consent to publish the report by patients and/or their parents if the identities of the patients are protected.

\section{Consent for publication}

This manuscript does not contain personal data/ images/ videos of any individual person, therefore consent for publication is not applicable according to the publication guidelines of BMC pediatrics.

\section{Competing interests}

We have no competing interests directly relevant to the content of this article.

\section{Funding}

This work was supported in part by the Research on Measures for Intractable Diseases Project and Health and Labour Sciences Research grants (H29-Nanchitou [Nan]-Ippan-013 and 015) from the Ministry of Health, Labour and Welfare, Japan, and the Practical Research Project for Rare/Intractable Diseases from the Japan Agency for Medical Research and Development, AMED (Grant Number JP19ek0109260 to SO), along with a Grant-in-Aid for Scientific Research (B) (Grant Number 17H04229 to SO) from the Japan Society for the Promotion of Science. These organizations had no role in the design of our study and collection, analysis, and interpretation of data and the writing this manuscript.

\section{Author Contributions}

The contributions of each author are as follows. AS, MI and SO were the principal investigators, taking primary responsibility for the paper. TT proceeded gastrointestinal endoscopy. KE, MS and TT performed the clinical management with helpful discussion regarding the completion of the work. All authors fulfilled the BMC 
Pediatrics' authorship criteria and agreed to be accountable for all aspects of the work in ensuring that questions related to the accuracy or integrity of any part of the work are appropriately investigated and resolved.

\section{Availability of Data and materials}

The datasets used for analysis during the current study are available from the corresponding author on request. All the relevant results are given in the manuscript can submit to BMC pediatrics if expected to submit.

\section{Acknowledgements}

We thank all physicians, the nursing staff, all patients, and their parents who participated in this study.

\section{Abbreviations}

AZT:azathioprine, BUD:budesonide, CD:Crohn disease, CRP:C-reactive protein, ESR:erythrocyte sedimentation rate, IBD:inflammatory bowel disease, IFN:interferon, IL:interleukin, PCDAI:Pediatric Crohn Disease Activity Index, PSL:prednisolone, TNF:tumor necrosis factor, 5-ASA:5-aminosalicytic acid, 6-MP:6-mercaptopurin

\section{References}

1. Lay D, Duhamel A, Behal H, Vasseur F, Sarter H, Michaud L, Gower-Rousseau C, Truck D. Growth pattern in paediatric Crohn disease is related to inflammatory status. J Pediatr Gastroenterol Nutr.2016; 63: 637-43.

2. Adedokun OJ, Xu Z, Gasink C et al. Pharmacokinetics and exposure response relationships of ustekinumab in patients with Crohn's disease. 2018; 154: 1660-71.

3. Dayan JR, Dolinger M, Benkov K, Dunkin D, Jossen J, Lai J, Phan BL, Pittman N, Dubinsky MC. Real world experience with ustekinumab in children and young adults at a tertiary care pediatric inflammatory bowel disease center. J Pediatr Gastroenterol Nutr. 2019; 69: 61-7.

4. Adegbola SO, Sahnan K, Warusavitame J et al. Anti-TNF therapy in Crohn's disease. Int J Mol Sci. 2018; 19: pii: E2244. doi: 10.3390.

5. Torio $\mathrm{M}$, Ishimura $\mathrm{M}$, Ohga $\mathrm{S}$ et al. Nephrolithiasis as an extra-intestinal presentation of pediatric inflammatory bowel disease unclassified. J Crohns Colitis. 2010; 4: 674-8.

6. Turner D, Levine A, Walters TD et al. Which PCDAI version best reflects intestinal inflammation in pediatric Crohn disease? J Pediatr Gastroenterol Nutr. 2017; 64: 254-60.

7. Ueno F, Matsui T, Matsumoto T, Matsuoka K, Watanabe M, Hibi T. Evidencebased clinical practice guidelines for Crohn's disease, integrated with formal consensus of experts in Japan. J Gastroenterol. 2013; 48: 31-72. doi: 10.1007/s00535-012-0673-1

8. Matsuoka K, Kobayashi T, Ueno F, Matsui T, Hirai F, Inoue N et al. Evidence-basedclinical practice guidelines for inflammatory bowel disease. J Gastroenterol. 2018; 53: 305-53. doi: 10.1007/s00535-0181439-1

9. Shinohara H, Kuranaga Y, Kumazaki M, Sugito N, Yoshikawa Y, Takai T, Taniguchi K, Ito Y, Akao Y. Regulated polarization of tumor-associated macrophages by miR-145 via colorectal cancer-derived extracellular vesicles. J Immunol. 2017; 199: 1505-15. 
10. Kaltsonoudis E, Voulgari PV, Konisiotis O, Drosos AA. Demyelination and other neurological adverse events after anti-TNF therapy. Autoimmun Rev. 2014; 13: 54-8.

11. Sandborn WJ, Rutgeerts P, Gasink C et al. Long-term efficacy and safety of ustekinumab for Crohn's disease through the second year of therapy. Aliment Pharmacol Ther. 2018; 48: 65-77.

12. Danese S, Bonovas S, Peyrin-Biroulet L. Positioning Ustekinumab in Crohn's Disease: From Clinical Evidence to Clinical Practice. J Crohns Colitis. 2017; 11: 1258-66.

13. Chavannes M, Martinez-Vinson $C$, Hart L et al. Management of paediatric patients with medically-refractory Crohn's disease using Ustekinumab: A multi-centred cohort study. J Crohns Colitis. 2018; 13: 578-84.

14. Shim JO. Recent advance in very early onset inflammatory bowel disease. Pediatr Gastroenterol Hepatol Nutr. 2019; 22: 41-9.

15. Luo J, Wu SJ, Lacy ER et al. Structural basis for the dual recognition of IL-12 and IL-23 by ustekinumab. J Mol Biol. 2010; 402: 797-812.

\section{Figures}

\section{Figure 1}

a

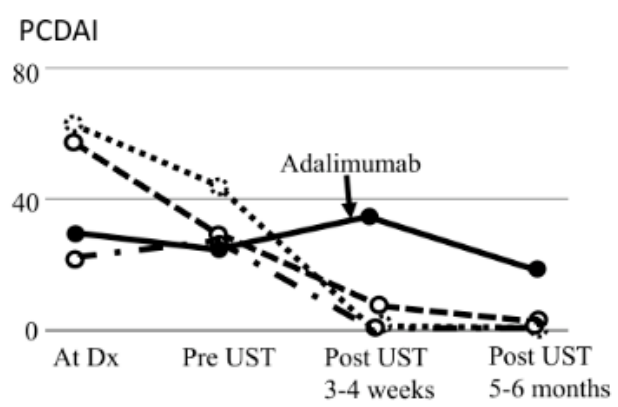

Alb (g/dL)
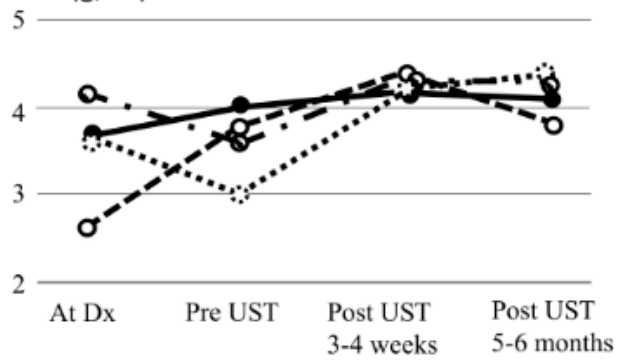

ESR $(\mathrm{mm} / \mathrm{hr})$

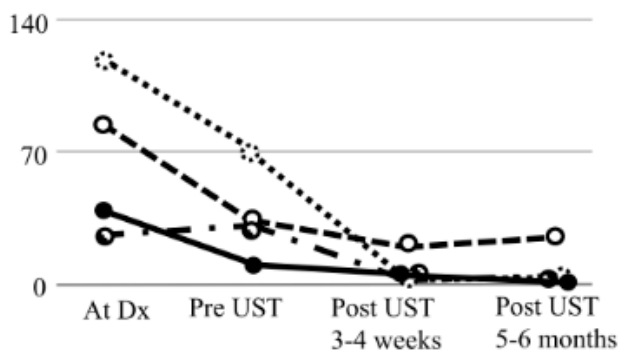

CRP (mg/dL)

15

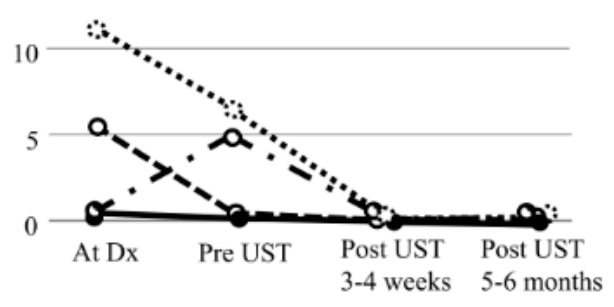

b

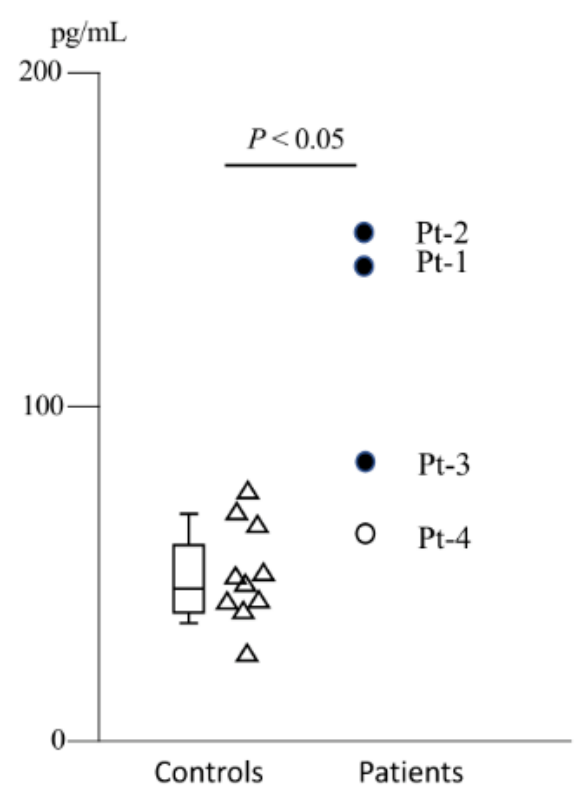

\section{Figure 1}

1a: Changes in laboratory indices and PCDAl. Dotted lines represent the UST responders of patients 1-3, and a solid line does the poor responder of patient 4. Dx: diagnosis, PCDAl: Pediatric Crohn Disease Activity Index, Pt: patient, UST: ustekinumab. 1b: Concentration of serum IL-12/IL-23p40. Closed and open circles represent responded and non-responded patients, respectively. Triangles represent serum levels of 10 healthy donors 
ranging from 24.7 and $74.9 \mathrm{pg} / \mathrm{mL}$. The boxplot exhibits the median (central line within each box), the 25th and 75th percentile values (box ends), and the 10th and 90th percentile values (error bars). The detection limit of IL12/IL-23p40 was $15 \mathrm{pg} / \mathrm{mL}$. 